\title{
De eso que se ha llamado interculturalidad en salud: un enfoque reflexivo
}

\author{
From what has been called interculturality \\ in health: a reflexive approach
}

\begin{abstract}
Alfredo Paulo-Maya ${ }^{1}$; Martha Cruz-Sánchez ${ }^{1}$
Forma de citar: Paulo Maya A, Cruz Sánchez M. De eso que se ha llamado interculturalidad en salud: un enfoque reflexivo. Rev Univ Ind Santander Salud. 2018; 50(4): 366-384. doi: http://dx.doi.org/10.18273/revsal.v50n4-2018010 @) (1)
\end{abstract}

\section{Resumen}

Desde finales del siglo XX y en un contexto global, en la mayoría de los países de América Latina la interculturalidad en salud se ha convertido en una política gubernamental que pretende atender las demandas de atención sanitaria y asistencia de las comunidades que presentan hablantes de una lengua indígena. Partiendo del supuesto de que la cultura étnica constituye una barrera que impide el acceso a los servicios de salud, se plantea como estrategia considerar las cosmovisiones de los "indígenas", con el fin de diseñar programas de salud "interculturales" que favorezcan la aceptación eficaz de la biomedicina. A pesar de compartir el mismo discurso, en México, Venezuela y Chile existen prácticas diferenciales relacionadas con las llamadas políticas interculturales en salud. Así, en el presente trabajo se tratará de identificar semejanzas y diferencias en la implementación de tales políticas; de igual forma, se tratará de evidenciar las contradicciones del enfoque intercultural en el marco de las políticas públicas y las condiciones socioeconómicas que enfrentan los pueblos indígenas en los tres países.

Palabras clave: Antropología reflexiva; Etnografía multisituada; Programas de salud; Indígenas; América Latina; interculturalidad en salud; Capacitación; Indicadores; Condiciones socioeconómicas.

\begin{abstract}
Since the end of the 20th century, broadly speaking, in most Latin American countries, intercultural health has become a government policy that seeks to meet the demands of care and assistance to communities where speakers of indigenous languages reside. As a point of departure, interculturality assumes that ethnic culture is a barrier that prevents access to health services. The proposed strategy includes harnessing an "indigenous" cosmovision in order to design "intercultural" health programs that will effectively implement biomedical techniques in the target population. While discourse regarding "interculturality" circulates in Mexico, Venezuela, and Chile, disparate practices related to so-called intercultural health policies are unfolding within these countries. Thus, the present article identifies similarities and differences in the implementation of such policies. Likewise, it highlights the contradictions of the intercultural approach within the framework of public policies and the socioeconomic conditions faced by indigenous peoples in the three countries.
\end{abstract}

Keywords: Reflexive anthropology; Multi-sited ethnography; Health programs; Indigenous people; Latin America; Intercultural health; Training; Indicators; Socioeconomic conditions.

1. Universidad Nacional Autónoma de México.

Correspondencia: Alfredo Paulo Maya. Dirección: República de Brasil No.33, Col. Centro, Ciudad de México, México, C.P. 06020. Teléfono: +5623 3137. Correo electrónico: alfpaulo@comunidad.unam.mx 
El enfoque teórico de la salud global ${ }^{1}$ conceptúa que las políticas en salud forman parte de un sistema mundial interconectado, cuyas expresiones locales no son uniformes, pues presentan diferencias importantes entre sí.

En el presente escrito concebimos a la interculturalidad en salud en los países de América Latina, como expresiones locales de grandes políticas a nivel global. Sin embargo, al recurrir al método etnográfico, más que centrarse en la descripción de una "región cultural" nuestra intención es dar cuenta cómo distintas dimensiones nacionales se encuentran interconectadas entre sí, ya que comparten una misma lógica sociocultural. Esta estrategia teórico-metodológica ${ }^{2}$ ha conceptuado como etnografía multisituada.

Vega $\mathrm{RA}^{3}$, señala que más que un sitio se trata de dar cuenta de una red de sujetos que participan en un campo común a nivel nacional e internacional, como lo es la salud reproductiva, por lo que es el investigador quien se desplaza de un lugar a otro, siguiendo a su objeto de estudio.

Si bien el estudio se centra en dos países, se dará cuenta de expresiones de las políticas de salud intercultural en cinco países de América Latina. El énfasis puesto en Chile y México obedece a que son los países, en donde por más de dos décadas se han implementado y desarrollado marcos referenciales de la llamada salud intercultural, por lo que han sido puntos de referencia para el resto de países en América Latina.

Se resalta que el autor decidió adoptar una postura reflexiva ${ }^{4,5}$ en la primer parte de este documento, no sólo para dar cuenta en forma crítica de la llamada salud intercultural, sino también para abordar la forma en que los antropólogos y profesionales de la salud le han abordado. Aclarando que recurriremos a la primera persona para describir, estamos claros que este tipo de escritura no es común según las convenciones de la antropología y la academia, por lo que apelamos a su comprensión.

El enfoque reflexivo plantea para el investigador social no sólo cuestionar en torno del sujeto bajo estudio, sino también sobre el papel del investigador y su práctica; es decir, dar cuenta del contexto en que se asumen los distintos abordajes teórico-metodológicos y sus implicaciones en la producción y reproducción del conocimiento; también pone entredicho la neutralidad ideológica y política del investigador, porque le obliga a ser consciente de su perspectiva teórica y política (intereses y posturas personales) y sus consecuencias en la vida de los sujetos bajo estudio.

De aquí la importancia de reflexionar sobre el porqué se priorizaron ciertas problemáticas y se descartaron otras. El marco teórico conceptual elegido; así como hacer explícitas las condiciones socioculturales que permitieron llevar a cabo la investigación ${ }^{4}$.

Mi postura reflexiva surge a partir de mi desempeño como co-responsable del programa de posgrado en el campo disciplinar de la antropología en salud de la Facultad de Medicina de la Universidad Nacional Autónoma de México. Ello obedeció a que, entre otros aspectos, pude depender de un trabajo de tiempo completo que me permitió acceder a diferentes posturas teóricas sobre la salud en las poblaciones de Hispanoamérica, ya sea a través de libros o revistas especializadas.

Así tuve acceso a la postura crítica de Ramírez $\mathrm{HS}^{6}$, quien ha señalado que en los programas de Salud Intercultural implementados en Bolivia, no se han expresado en cambios significativos en la calidad de atención en centros médicos y hospitales, así tampoco ha impactado en los indicadores epidemiológicos. De hecho, nos propone contemplarlos como estrategias gubernamentales que tienden a ocultar los conflictos étnicos, caracterizados por grandes diferencias económicas y políticas.

Por otra parte, ser profesor invitado a eventos académicos en Perú, Chile, Venezuela y México me permitió establecer relaciones de interlocución con diferentes funcionarios relacionados con los programas de Salud Intercultural, sobre todo, con diversos personajes encargados de su operación, en su mayoría hablantes de una lengua Indígena.

En este proceso jugó un papel clave la interlocución con Andrés Cuyul, líder mapuche en la región de Temuco Chile, quien es trabajador social y estudiante del Doctorado en Salud Colectiva de la Universidad Autónoma Metropolitana, campus Xochimilco. El trabajo comunitario realizado en México y en Chile, nos llevó a discutir críticamente los alcances de las políticas interculturales en Salud.

Paulatinamente, empecé un proceso reflexivo profundo y a asumir una postura crítica sobre los planteamientos que sustentan los programas de salud para los pueblos indígenas en América Latina y de los cuales he sido partícipe, así como, de las formas en que los antropólogos hemos abordado la llamada salud Intercultural. 
La crítica a los programas de salud intercultural, la realizo con la intención de replantear sus enfoques y objetivos. De hecho, considero que el enfoque reflexivo y crítico de la antropología podría contribuir a la generación de conocimientos tendientes a mejorar la condición de salud en los pueblos indígenas en América Latina.

Mi reflexión abarca mi participación en una asociación civil llamada "Yolpaltli" en el 2004, la cual tenía como objetivo sensibilizar a las secretarías de salud, sobre las "adecuaciones interculturales" a hospitales y clínicas ubicadas en regiones indígenas y, que de manera indirecta influiría en el diseño de una política nacional que esperaba atender la salud de las poblaciones indígenas en México e incluso, favorecerían las líneas operativas de la Dirección de Salud Intercultural.

Estar adscrito a la Facultad de Medicina de la UNAM, me permitió ser profesor y coordinador en dos diplomados internacionales en Salud Intercultural en Ayacucho Perú, patrocinado por una Asociación Civil (Amares) y la Comunidad Económica Europea; ser conferencista en dos Congresos de Salud Indígenas en Venezuela organizados por el Ministerio del Poder Popular para la Salud (MPPS) y la Organización Panamericana de la Salud/Organización Mundial de la Salud (OPS/OMS); y finalmente, profesor invitado del diplomado Salud y Pueblos Indígenas organizado por Red de Salud Intercultural Warriache y la Facultad de Ciencias Médicas de la Universidad de Santiago de Chile.

Posteriormente, fui asesor de una asociación civil que a través del Instituto Nacional de Salud Pública en México, diseñarían un programa para la atención de los problemas de salud de los pueblos indígenas desde un enfoque de la equidad y género.

\section{El caso chileno}

En la región aledaña a la ciudad de Temuco existen tres servicios de salud que, si bien dependen de la injerencia del Ministerio de Salud de Chile (MINSAL), sus formas de organización y vinculación con las comunidades difieren entre sí. Cuando preguntaba al personal de salud sobre estas diferencias tan notorias, sus respuestas me conducían a su causa primera; principalmente, a la gestión política de las organizaciones mapuches.

De esta forma, pude identificar que se trata de un proceso social, que lejos de ser de carácter unívoco, se ha manifestado de múltiples formas, la mayoría de las veces contradictorias entre sí. Me refiero, sobre todo, a las ideas y acciones que dieron origen a las "transformaciones culturales de los hospitales y servicios de salud ubicados en los "territorios indígenas".

Mis primeras incursiones en la región me llevaron a reconocer lo difícil que resulta poder definir relaciones de interlocución con los líderes y la población mapuche. Posteriormente, noté que la dificultad no se debía a una reticencia en dialogar con un extraño, como si por el hecho de ser un invitado de los winkas (blancos chilenos) me colocaba en una condición que me asociaba a sus intereses.

Mis visitas a esta región durante los años 2004, 2010, 2013 y 2015 favorecieron el establecimiento de las relaciones de interlocución y de reciprocidad entre los diversos sectores de la población mapuche, los que a su vez suelen apreciar a quienes aceptamos compartir sus costumbres, como la reunión alrededor del fogón del hogar (ruka) en el que los asistentes se reparten bebidas y alimentos mientras dialogan y acuerdan durante varias horas; este patrón, es notorio en la ceremonia de petición (nguillatún) donde se intercambian rezos, bailes y comida durante la mayor parte del día. Al respecto, quiero señalar que en los múltiples espacios $\mathrm{y}$ ceremonias en las que he participado, los winkas chilenos han permanecido hasta su finalización en contadas ocasiones.

Debo reconocer que mis vínculos de interlocución se potenciaron por el gran imaginario y aprecio que tienen sobre lo mexicano. Las travesías de los jinetes y sus caballos que pueden verse en películas como las de Antonio Aguilar y escucharse en la música bravía de los corridos revolucionarios son fascinantes. No menos importante fue mi fenotipo y, en parte, mi corporeidad ruda porque ambos me permitieron diferenciarme de los winkas chilenos.

De este modo, pude conocer el peso de las relaciones racializadoras dominantes en $\mathrm{Chile}^{7}$ que tantos problemas me habían causado en Santiago y la ciudad de Temuco $^{1}$; donde fui víctima de comentarios y acciones discriminatorias por mi fenotipo identificado como peruanito o boliviano; pero, sobre todo, porque tenía conocidos en el territorio ocupado por las comunidades mapuches. Sin embargo, también reconocí la existencia de una especie de etnoracismo: algunos

1 En el presente año, el presidente Sebastián Piñera al firmar el proyecto de migración que afecta principalmente a los migrantes haitianos, venezolanos, colombianos; peruanos y bolivianos expresó: "Ha llegado el momento de poner orden en este hogar que compartimos". 
mapuches comprometidos con sus reivindicaciones étnico-nacionalistas, al abordar temas políticos y de organización comunitaria, establecían un diálogo menos conflictivo con un mexicano que con los winkas chilenos $^{8}$.

Otras formas de racialización están asociadas con el reconocimiento oficial de los saberes indígenas, mientras que el discurso gubernamental enfatiza la importancia de preservarlo, el reconocimiento oficial a sus principales demandas sociales es negado, entre ellas: el territorio, el manejo de recursos y la organización basada en los usos y costumbres. Esto se ha visto reflejado en los diferentes escritos del Ministerio de Salud o instancias académicas chilenos que, por un lado, resaltan "la participación activa de los pueblos originarios en la Red Sanitaria del Servicio" y el respeto a su cosmovisión; mientras que por el otro, tienden a silenciar la participación y gestión de diversos sectores indígenas en los servicios de salud y, sobre todo, a silenciar las resistencias y negociaciones llevadas a cabo por las organizaciones mapuches (muchas de ellas violentas) en defensa del territorio, así como la participación de la población en general.

Otra forma, son los convenios de colaboración entre las organizaciones mapuches y las universidades públicas chilenas; estos suelen enfocarse en obtener información que se convertirá en producción científica; pero poco o ningún interés se ha mostrado por dar un aval académico a sus actividades de organización comunitaria, manejo de plantas medicinales y prácticas terapéuticas, entre otras.

\section{Antecedentes de los proyectos de salud en territorio mapuche}

Muy cerca del fin de la dictadura de Pinochet, el gobierno de Chile enfrentaba un grave problema en la región donde se ubica el Hospital Makewe: la elevada prevalencia de la morbilidad y mortalidad por infecciones respiratorias agudas, especialmente, la tuberculosis. Entre tanto, bajo un régimen de propiedad privada, algunas organizaciones mapuches intensificaron sus protestas en reclamo de sus territorios originales, reconocidos como parte del Estado Chileno en los mapas oficiales; y contra los despojos de los bosques por parte de los rurales y las empresas.

Así, en una coyuntura marcada por la transición democrática y la intensificación de las protestas, el "nuevo gobierno chileno" mostró apertura hacia el diálogo, en ese sentido, recurrió a especialistas que tuvieran cierto conocimiento de las comunidades mapuches y sus problemas de salud, particularmente los médicos, muchos de los cuales se encontraban exiliados.

Para la región de Temuco resultó importante incorporar al Ministerio de Salud de Chile al médico Jaime Ibacahe, quien habla el idioma mapudungun y, en su momento, me comentó que fue parte de una generación de jóvenes médicos que compartían los ideales socialistas y libertarios del presidente Salvador Allende. Su vocación, lo llevó a convivir y atender un sinnúmero de familias mapuches, actividad que interrumpió con el golpe militar, exiliándose en Europa.

A finales del siglo XX, diversos caciques (líderes) junto con el apoyo de los representantes comunitarios de todas las provincias (que se convertirían en promotores de salud) dieron origen a la "Asociación Indígena para la Salud Maquehue-Pelale" bajo formas de organización enraizadas en el reconocimiento y reconstrucción del territorio originario. Esta asociación consensó y gestionó ante el Ministerio de Salud (MINSAL), el establecimiento del Hospital Makewe donde estuvo ubicado una Iglesia Anglicana. Bajo la subvención del Minsal y a pesar de su inicial oposición, fue designado como director del Hospital el Indígena Mapuche Francisco Chureo.

Desde sus inicios, el Minsal ha mostrado al Hospital Makewe como un modelo exitoso de participación indígena en la gestión hospitalaria; sin embargo, con el paso del tiempo se han presentado recurrentes recortes presupuestarios que han comprometido los salarios del personal médico, generando su movilidad.

Los principales problemas se relacionan con una disminución significativa de los recursos destinados a reforzar las formas de organización comunitarias y las prácticas terapéuticas mapuches; esta situación ha llevado al director del hospital a gestionar recursos externos al Minsal. En ese sentido, se plantearon convenios con universidades canadienses y australianas, para realizar cursos, talleres y tours relacionados con la cultura y la medicina mapuche, esta actividad le ha significado ser calificado de "sacar provecho personal".

Por su parte, el Minsal a través del Programa de Salud con Población Mapuche en la Araucanía ha favorecido a través de los medios de comunicación masiva, locales e internacionales, la difusión de lo que han denominado política pública exitosa.

Para julio de 2003, gracias al apoyo del posgrado, tuve la oportunidad de conocer por primera vez el Hospital 
Makewe, la ciudad de Temucó y las comunidades mapuches. De hecho, mi primer vínculo con la gente de Boroa Filulawen no fue muy grato, pues se abordó el contenido de una carta en que se hablaba de un supuesto "aprovechamiento" del trabajo del pueblo mapuche; asimismo, me sorprendió su conocimiento sobre los movimientos étnicos del resto de América y el particular interés por el Movimiento Zapatista de Liberación Nacional (EZLN) en Chiapas, México.

En sus ideas sobre la integración de las medicinas tradicionales y la salud, hacían referencia a la "cosmovisión mapuche". Ubicando la salud en el centro, el equilibrio dependía del territorio, la organización comunitaria, el ecosistema y la autonomía; es decir, se trata de una reelaboración de la "cosmovisión tradicional" que fundamenta un proyecto étnico de reivindicación territorial (nación).

Lo expuesto me llevó a reflexionar sobre el proceso de globalización y la expansión de los discursos étnicos en Hispanoamérica; que si bien éstos no se expresan de manera univoca, sí se trata de una especie de flujo que tiene configuraciones locales. Un ejemplo de ello es la recurrencia de temas sobre la autonomía, nacionalismo, derechos de los pueblos indígenas; cosmovisiones, interculturalidad, etc. Muchos de los cuales se adquirieron en universidades chilenas, hispanoamericanas o europeas.

En el campo de la salud, se ha visto reflejado con la paulatina presencia de profesionales mapuches en los servicios de salud municipales, asociaciones civiles o desempeñando cargos directivos en el ministerio de salud, en particular, el Programa Especial de Salud y Pueblos Indígenas (PESPI), esta presencia se ha traducido en confrontaciones entre funcionarios chilenos y los de origen mapuche, que han logrado ascender y posicionarse políticamente, con la consecuente influencia en las actividades de salud implementadas en las regiones indígenas.

\section{De eso que llaman interculturalidad en salud: configuración chilena}

En relación con la denominada interculturalidad en salud, hasta donde he llegado a indagar, en Chile las primeras nociones fueron elaboradas por un grupo de médicos y antropólogos encabezadas por el Dr. Jaime Ibacache. Durante su exilio por Europa visitó la Università La Sapienza en Roma, Italia; donde conoció a Luca Citarella, responsable de cursos de antropología médica y quien le compartió sus ideas sobre la interculturalidad en el campo de la educación y su aplicación en la salud.

Ibacache me explicó que, si bien consideraba a la interculturalidad como la relación entre culturas, la aplicación en el ámbito de la salud la había pensado originalmente como una estrategia de atención en un espacio geográfico y clínico, y lo delimitó como: "la capacidad de moverse equilibradamente entre conocimientos, creencias y prácticas culturales diferentes respecto a la salud y la enfermedad, la vida y la muerte, el cuerpo biológico, social y relacional. Percepciones que a veces pueden ser incluso hasta contrapuestas".

Para Ibacache el equilibrio hace referencia a las nociones de la "cosmovisión mapuche"; las cuales son replanteadas en el desarrollo de una actitud de equidad, aprender del saber de la gente para transformar la realidad; actitud epidemiológica, con enfoque territorial, social y cultural de los problemas de salud y la actitud de participar, entendida como el ser parte del espacio de la gente y sus estrategias de salud.

Las ideas antes expuestas, le permitieron hacer operable un programa de salud en el territorio mapuche aledaño a la Ciudad de Temuco. Lo que nunca imaginó fue que sus ideas llegarían a ser retomadas por diversos investigadores sociales de manera acrítica; yo agregaría, como si se tratara de un concepto teórico que pretendiera explicar las formas de atención hacia los pueblos indígenas de América.

En 1996 el MINSAL diseñó el PESPI ${ }^{10}$, cuyo objetivo "pretende incorporar la participación de los pueblos originarios en la formulación y evaluación de los Planes de Salud Intercultural de la Red Sanitaria del Servicio, a través de Mesas de Salud Intercultural Local, las cuales se conforman por representantes de los pueblos originarios y personal del Minsal y del Hospital.

Bajo la idea de la interculturalidad en salud entendida como "reconocimiento, salvaguarda, fortalecimiento y complementariedad de los sistemas culturales de salud de los pueblos indígenas" ${ }^{10}$ se promovió la creación de facilitadores y asesores interculturales, a través de un equipo motor/ejecutor a cargo del Minsal, a los que se capacitó para "mejorar la pertinencia cultural de las actividades de salud"10 como la sensibilización y capacitación de funcionarios en el conocimiento de ceremonias y medicina ancestral. 
Como puede notarse en la estrategia antes descrita, aspectos claves que dieron origen al Hospital de Makewe fueron omitidos en los documentos del MINSAL, entre ellos: el reconocimiento y reconstrucción del territorio originario, la organización social comunitaria (más que valerse de ella) y su gestión en los proyectos de salud comunitarios $^{11}$.

Por otra parte, si bien muestra similitudes con la estrategia operativa de Ibacahe; también son banalizados aspectos importantes como hablar el idioma indígena y, en palabras del propio Ibacache: "Aprender del saber de la gente y transformar la realidad; ser parte del espacio y sus estrategias de salud y una base epidemiológica con enfoque territorial, social y cultural."

Lo antes expuesto me ha llevado a reflexionar que la interculturalidad en salud en Chile ha tenido un uso pragmático a través del tiempo, sobre todo, por parte de las instancias del Minsal; por ejemplo, para el 2017 el Pespi argumentaba que la "inequidad en salud" se expresaba en "perfiles epidemiológicos diferenciados" entre la población indígena y la no indígena, la cual eran provocadas por "barreras culturales"l2.

Se plantea como estrategia operativa, la intervención de un facilitador intercultural para mejorar la adherencia a los tratamientos, asimismo la pertenencia cultural en los servicios de salud y su "sensibilización" sobre la realidad cultural de los pueblos indígenas; en esta ocasión, la interculturalidad refiere reconocimiento de la cosmovisión de los indígenas ${ }^{13}$.

Es importante destacar la participación de antropólogos contratados por el Minsal en la delimitación de estas estrategias de intervención; entre ellos, una de sus principales funcionarias. Es por esta visión antropológica que en los documentos oficiales del Minsal se hagan referencia a nociones sobre la cosmovisión, interculturalidad y pertenencia cultural; siendo esta última, reducida a "diferencias lingüísticas, identitaria y en la percepción de problemas de salud ${ }^{13}$. Es decir, se nota un uso pragmático de las categorías antropológicas y su subordinación a las lógicas biomédicas.

Sobre lo expuesto quiero señalar, que la interculturalidad en salud aplicada en Chile es un conjunto de nociones que tiene como principal función justificar acciones gubernamentales relacionadas con la implementación de los servicios médicos en poblaciones indígenas $\mathrm{y}$, no tanto en la búsqueda de mejorar los indicadores de bienestar
Un último punto por resaltar y no menos importante es la evaluación. Dado que la interculturalidad en salud es una política gestada desde el MINSAL, es de suponerse que se rige por lo criterios de evaluación biomédicos, en donde los conceptos de "medición" y de "variable" resultan fundamentales.

No obstante, al revisar los documentos relacionados del PESPI, son notarias la ausencia de evaluaciones y referencias a problemas identificados a través de los perfiles epidemiológicos ${ }^{14}$ de los que debería partir el programa.

Para entenderlo mejor, en un documento del 2017 se hacen referencias a las investigaciones epidemiológicas como de manejo interno, es decir, no públicas para las regiones de Tarapacá, Arica Parinacota, Antofagasta, Los Ríos, Bio Bio, Araucanía, Los Lagos y Magallanes ${ }^{12,15-16}$.

Los pocos datos epidemiológicos señalan que existen indicadores clave como la mortalidad infantil; pero sin tener criterios claros de lo que caracteriza lo indígena en Chile. El Plan para Pueblos Indígenas ${ }^{12}$ indica:
Los niños indígenas menores de 5 años tienen 2,6 veces más riesgo de morir que los niños no indígenas; riesgo que aumenta a 3,6 entre los 5-9 años; y que alcanza los niveles más críticos entre los 20-24, estrato de edad en que los indígenas tienen un riesgo 3,4 veces más elevado.

Otro caso es el de las enfermedades cardiovasculares en el archipiélago de Chiloe donde se señalan diferencias significativas entre los "indígenas y no indígenas" sin precisar cómo se identificó a la población indígena:
En el área estudiada -tal como ocurre con la mortalidad general- son los hombres pertenecientes a pueblos indígenas los que presentan el mayor riesgo de morir por enfermedades cardiovasculares (ECV), alcanzando una tasa de 247,8 por 100.000 . Aunque muy por debajo de esta cifra, las mujeres indígenas exhiben la segunda tasa más alta $(177,2$ por 100.000); se sitúa, luego, la tasa en hombres no indígenas (172,4 por 100.000); y, por último, las mujeres no indígenas con la tasa más baja $(119,4$ por 100.000). ${ }^{12}$

Bajo esa misma lógica, se señala la mayor tasa de mortalidad por cáncer ( la población indígena y no indígena.

(...) el mismo estudio identificó una tasa de 148,7 por 100.000 para la población indígena y de 50,8 por 100.000 para población no indígena; es decir, que el 
riesgo de morir por estas causas entre los indígenas triplica el de los no originario. Respecto de las tasas de suicidio se ha identificado para trienio 2004-2006 el riesgo de suicidio entre los pueblos indígenas es 2,4 veces mayor que en población no indígena ${ }^{12}$.

Finalmente, la tasa promedio de incidencia de tuberculosis en la población indígena fue de 37,3 casos por 100.000 habitantes y de 12,9 por 100.000 en la población no indígena. Por otra parte, sin exponer datos precisos, se resaltan la presencia de altas tasas de suicidio y salud mental; a pesar de que el documento se indica que estas condiciones patológicas están "fuertemente asociadas a determinantes sociales de la salud", nunca se les menciona ni se da a entender a cuáles se está refiriendo ${ }^{12}$.

Llama la atención el silenciamiento de los conflictos históricos en las regiones donde se concentra la población indígena, muchos de ellos violentos y están relacionados con los despojos y el control de la tierra por parte de las instancias gubernamentales y empresas forestales; también, con las relaciones interétnicas donde predominan los procesos de racialización ${ }^{17}$.

Apenas se resalta una relación que nunca es definida entre las "desigualdades en situación de salud" y la "marginación". Solo bajo esa lógica, se establece el argumento que mejorando la "pertinencia cultural" se favorece el acceso de la población a la atención de los servicios médicos; sin embargo, es notoria la banalización de los estudios epidemiológicos realizados por el mismo PESPI; un ejemplo de ello, son los registros censales que dan evidencia de la presencia de población indígena en los principales centros urbanos de Chile y el incremento de las tasas de morbi-mortalidad asociadas a la hipertensión y diabetes mellitus ${ }^{15,16}$.

Transcurridos casi 20 años del establecimiento de los hospitales y puestos de salud, bajo el enfoque intercultural, en la región de la Araucanía, llama la atención que para el 2017 el PESPI, haga referencia a un perfil epidemiológico en la que precisamente los datos de esa región están ausentes.

En 2015, pregunté en el Hospital Makewe por los datos de morbi-mortalidad asociados a tuberculosis. Se me indicó que se encontraban en una base de datos; pero que si se querían consultar los tenía que organizar por año, lo cual me intrigó pues si algo caracteriza al MINSAL es el manejo de los datos epidemiológicos. Logré indagar que las bases de datos son enviados al MINSAL de manera esporádica y nunca habían recibido un comentario o recomendación.
Por su parte en Boroa, la información de los servicios de salud se relaciona básicamente con problemas asociados al síndrome metabólico (hipertensión y diabetes), esta información es concentrada y enviada a las oficinas del MINSAL, pero nunca han recibido ninguna recomendación.

De este modo me di cuenta de que en ambos espacios donde se ofrecen servicios de salud a la población indígena, la planeación de actividades y recursos no se hacen necesariamente tomando en consideración los perfiles epidemiológicos.

La poca información concerniente a las poblaciones indígenas en Chile me ha llevado a reflexionar y tomar una postura crítica sobre las propuestas de la salud intercultural. En ese sentido, el "contrarrestar" las altas tasas de morbi-mortalidad (diabetes mellitus, afecciones cardiovasculares, cáncer, tuberculosis y suicidio) a través de la cosmovisión ancestral, las adecuaciones culturales hospitalarias y la presunta participación comunitaria es una actitud irresponsable, cómplice de los procesos de silenciamiento de las condiciones de subordinación política, económica y racializadora de la población indígena de Chile.

\section{El caso de México}

A inicio del 2001, la presidencia de la república en México era encabezada por Fox Quezada, representante del Partido Acción Nacional y cuya administración marcó el final de un periodo de más de 70 años de gobierno del Partido Revolucionario Institucional (PRI).

$\mathrm{Su}$ gobierno se caracterizó por continuar con las políticas de corte "neoliberal", iniciadas por el PRI años atrás. Impulsó las reformas: la fiscal que se expresó en el incremento de impuestos; la laboral que transformó el sistema de administración de las pensiones y el tipo de contratación de los trabajadores; y la energética, que favoreció la participación de la iniciativa privada en áreas como la producción de energía y petróleo; todas estas, afectaron los derechos y el ejercicio de la ciudadanía en México.

El gobierno mexicano impulsó la implementación del Sistema de Protección en Salud o Seguro Popular con la intención de dar atención a los "factores de desigualdad"; las diferencias en el acceso y hacer efectivo el derecho a la salud. Objetivos que nunca logró; pero que bajo el modelo de "pluralismo estructurado" permitió la participación gradual de la iniciativa privada en el sector la salud ${ }^{18}$. 
En el ámbito de la política hacia los pueblos indígenas se da fin al "indigenismo institucionalizado". Se cancela el Instituto Nacional Indigenista y se crea la Comisión Nacional Para el Desarrollo de los pueblos indígenas con el fin de abatir rezago social en pueblos originarios. Sin embargo, en torno de la noción de "desarrollo" se critica el paternalismo del Estado y se atribuye la situación de los pueblos indígenas a la "marginación" económica y política ${ }^{19}$.

Después de casi seis años de negociación entre el Gobierno Federal y el EZLN se promulga, en el año 2001, la Ley Cocopa en la que, supuestamente, se retoman los compromisos de los Acuerdos de San Andrés firmados en 1996, desconocidos por el grupo disidente y cuyo principal argumento fue que limitaban los Derechos de los pueblos indígenas, tales como el uso colectivo y disfrute de los recursos naturales y territorios, impedía su autonomía y la libre determinación, aspectos que el gobierno mexicano había ratificado el Convenio 169 de la $\mathrm{OIT}^{20}$.

Debo resaltar que esta forma de banalizar las exigencias y condiciones sociales que enfrentan las poblaciones indígenas, fue característico de las políticas encaminadas a atender las necesidades de este sector de la sociedad. De la cual forma parte el programa de salud intercultural, como desarrollaré a continuación.

En agosto de 2002 la Secretaría de Salud, a través de la Dirección General de Planeación y Desarrollo en Salud, crean la Dirección de Medicina Tradicional y Desarrollo Intercultural $^{21}$, con el objetivo de:

\begin{abstract}
Definir e impulsar la política intercultural en la oferta de los servicios institucionales, con una visión acorde con las expectativas de la sociedad en un marco de respeto y promoción de los derechos humanos, la perspectiva de género y una visión innovadora que promueve la interrelación con la medicina tradicional mexicana y las denominadas Medicinas Complementarias, presentes en las preferencias de la sociedad ${ }^{22}$.
\end{abstract}

Personalmente conocí a su director el Dr. Armando Almaguer en el 2001, cuando visitó el Departamento del Historia de la Medina de Facultad de Medicina de la UNAM para solicitar asesoría relacionada con la "legalización de la medicina tradicional".

En ese periodo, colegas de distintas universidades e institutos fueron visitados por él para asesoría e información, que le permitiera definir las líneas de trabajo de la dirección a su cargo. A través del portal web de la Secretaria de Salud solía agradecer la participación de antropólogos, biólogos, médicos y exfuncionario.
Como parte del proceso de consolidación de las líneas de trabajo de la Coordinación de Salud para los pueblos indígenas, dependientes de la Dirección General de Planeación y Desarrollo en Salud (al igual que la Dirección de Medicina Tradicional y Desarrollo Intercultural) se lanzó un concurso público para diseñar un curso que pretendía sensibilizar a los funcionarios del sector salud, en asuntos interculturales.

La licitación fue ganada por la asociación civil llamada Yolpahtli: Servicios de salud con calidad intercultural en pueblos amerindios. Encabezada por el Dr. Roberto Campos y de la cual formé parte; capacitamos al personal de la Secretaría de Salud, de algunas de las entidades que concentraban población indígena entre el 2003 y 2004.

Originalmente se esperaba sensibilizar a los funcionarios, con la expectativa de que estos posteriormente solicitaran asesorías relacionadas con la implementación de programas de salud intercultural en las entidades bajo su injerencia. Sin embargo, su presencia fue esporádica, siendo notoria la ausencia de representantes en el Estado de Oaxaca y Chiapas.

Los responsables de diseñar los contenidos e impartirlos fuimos básicamente profesores del Departamento de Historia y Filosofía de la Medicina de la Facultad de Medicina; del Instituto de Investigaciones Antropológicas, ambas instancias de la Universidad Nacional Autónoma de México y del Herbario del Centro Médico Nacional.

No puedo hablar por todos mis compañeros que participaron en el proyecto de capacitación de una Dirección de la Secretaría de Salud; pero la mayoría, nos sentíamos identificados con las reivindicaciones de la organización político-militar, formada en gran parte por indígenas tzeltal, tzotzil, chol, tojolabal y mam del Estado de Chiapas; de esta manera veíamos la viabilidad del México profundo planteado por Bonfil $\mathrm{G}^{23}$.

En lo personal simpatizaba con las ideas que enfatizaban el "uso de la antropología" para mejorar los servicios de salud en comunidades indígenas: la capacitación de los funcionarios, tal como veníamos haciendo con los estudiantes de la Facultad de Medicina de la UNAM, sería suficiente para generar las transformaciones en los servicios de salud brindados en la población indígena.

Las experiencias referidas, sugerían que era posible generar transformaciones en los hospitales y servicios de salud, después de que fuera realizado un diplomado en salud intercultural en la ciudad boliviana de Potosí, 
en coordinación con la Facultad de Medicina de la UNAM y la cooperación italiana ${ }^{24}$.

De igual forma me parecía una buena oportunidad para poner a prueba los planteamientos de Carlos Zolla, quien promovió la incorporación de la medicina tradicional en los hospitales durante su gestión como Subdirector de Bienestar Social y Director de Investigación y Promoción Cultural del Instituto Nacional Indígena; de hecho, se señalaba la pertenencia del Hospital Mixto de Cuetzalan en Puebla, pues la incorporación de los médicos indígenas había favorecido la atención de la población indígena ${ }^{25,26}$.

Los cursos de sensibilización se conformaron por los siguientes módulos ${ }^{27}$ :

1. Una visión general sobre la medicina intercultural. De la interculturalidad forzada a la interculturalidad apropiada.

Origen y desarrollo de la interculturalidad en México.

2. La pluriculturalidad y Estado-Nación en México. ¿México, país multiétnico y pluricultural? La pluriculturalidad y las leyes en México.

3. Modelos médicos y la interculturalidad. Los modelos médicos en México.

Características y funciones de los modelos médicos.

Caso 1. Los servicios administrativos y biomédicos.

4. La enseñanza de la relación del personal de salud con el paciente en la medicina académica.

5. La relación del personal de salud/paciente: el problema de la asimetría.

La relación médico-paciente en el modelo médico hegemónico

Caso clínico 1: Relación médico paciente.

6. La cosmovisión de los pueblos indios de México.

Generalidades sobre la cosmovisión.

Cosmovisión: Algunos ejes temáticos significativos para el proceso salud-enfermedad.

7. Procesos bioculturales en México: embarazo/parto/ puerperio, sexualidad y muerte.

Embarazo, parto, puerperio.

Sexualidad.

Muerte.
8. La alimentación y la nutrición en contextos interculturales

9. Las enfermedades desde un enfoque antropológico: epidemiología sociocultural y síndromes de filiación cultura.

Las diversas perspectivas sobre la enfermedad.

La epidemiología sociocultural: los síndromes culturalmente delimitados.

10. La salud mental en contextos interculturales.

11. Los tratamientos populares y el personal de salud. Relevancia de la herbolaria

Crónica histórica de la herbolaria mexicana, siglos XIX y XX.

12. De la teoría a la acción para la atención de problemas de salud en contextos Interculturales.

13. La ética en la relación intercultural
La tolerancia.
Racismo.
Caso sobre ética e interculturalidad

14. Experiencias interculturales desde las instituciones de salud

Una trayectoria en la medicina intercultural

15. La atención del personal de salud hacia el paciente en situaciones interculturales: de la teoría a la práctica.

La organización de los servicios de salud.

La calidez de los servicios de salud.

16. Hacia la construcción de un diálogo intercultural en salud.

17. Metodología de la investigación acción.

18. Esquema del proyecto y propuesta pedagógica.

A la fecha, desconozco si los cursos de sensibilización cumplieron su objetivo en las diferentes entidades. Pero lo que es claro es que contribuyeron para delimitar las líneas de trabajo de la Dirección de Medicina Tradicional y Desarrollo Intercultural; aunque, también evidenciaron el protagonismo en sus instancias rectoras la Dirección General de Planeación y Desarrollo en Salud de la Secretaría de Salud.

Como se ha señalado, la "estrategia de capacitación" fue puesta a concurso público (licitación) por parte de la Secretaría de Salud, por lo que llama la atención que 
nunca se evaluara su "eficacia" o que no nos solicitaran nuestros instrumentos de valoración. Al parecer, la asistencia de profesionales de la salud resultó suficiente.

Sin embargo, mis reflexiones me han llevado a cuestionarme por los criterios más adecuados para evaluar los cursos de sensibilización en salud intercultural. Por ejemplo, si se tratara de un aprendizaje basado en competencias (que es la forma dominante en la enseñanza biomédica) ¿Cuáles serían los conocimientos y habilidades concretas por valorar? Lo que sí me ha quedado claro, es que para los académicos y sobre todo las instancias gubernamentales del sector salud, encargadas de la sensibilización intercultural, eso parece no preocuparles.

En el 2007 fui invitado a participar como asesor "emergente" en un proyecto que fue puesto a concurso por el Centro Nacional de Equidad de Género y Salud Reproductiva de la Secretaría de Salud Federal. Se trataba de diseñar una propuesta de servicios de salud, que pretendía proporcionar una atención con calidez, identificar los problemas locales y capacitar a las líderes de la comunidad en la promoción comunitaria en salud. De esta manera, la estrategia consistió en el diseño de manuales de procedimientos y resolución de problemas; y la capacitación de un grupo multidisciplinario que se encargaría de su implementación.

La idea de conformar equipos de facilitadores interculturales (trabajador social, antropólogo y enfermera que hablara un idioma indígena) fue retomada de las experiencias en Chile.

Mi participación fue muy polémica, porque desde un inicio detecté incongruencias entre los objetivos y los procedimientos, pero se me aclaró que se trataba de "salvar la situación". Así que explícitamente solo me comprometí a organizar un encuentro para evaluar la forma en que los "facilitadores interculturales" habían implementado el manual en su fase exploratoria.

En la evaluación, mi equipo de trabajo encontró inconsistencias en los contenidos de la capacitación orientados a "empoderar a las mujeres", asimismo, dificultades en la conformación de los equipos de facilitadores interculturales, siendo patente la discriminación hacia los hablantes de un idioma indígena; pero lo más notorio fue la omisión de la violencia que, si bien era un objetivo del proyecto, nunca fue tratado por la estrategia. Al respecto, una de las asesoras del proyecto me señaló "porque habría que hacerlo, era parte de los requerimientos para que el proyecto fuera aprobado".
A pesar de mis observaciones, los responsables del proyecto terminaron de diseñar el "manual de procedimientos". Pasado el tiempo logré dialogar con una de las principales asesoras del proyecto sobre los manuales de intervención. Al preguntarle por su viabilidad me indicó que tampoco eran operables y refirió que esto era "porque no había evidencia de intervención; caímos en el mal de hablar o hacer por las poblaciones, pero sin ella".

Al preguntarle por la pertinencia de incluir el enfoque intercultural en salud me explicó que "la Interculturalidad es la bandera para saber o hacer bien las cosas con las poblaciones, se veía como la mejor forma de acercamiento".

Finalmente, se habló sobre la "politización" y el protagonismo de los funcionarios de la Secretaria de Salud y el equipo de trabajo en torno del proyecto, así como la ausencia de información una vez entregados el manual de procedimientos.

Con mi segunda incursión como asesor en los proyectos licitados por la Secretaría de Salud Federal, reflexioné sobre la existencia de patrones culturales entorno de las instituciones públicas y los programas encargados de brindar servicios de salud a las "poblaciones vulnerables". Me refiero al peso otorgado a la capacitación con el fin de dar solución a los problemas estructurales.

En el caso de la población indígena, la salud intercultural parece sugerir que su bienestar depende de capacitación del personal de salud y no las condiciones históricas de explotación y subordinación económica y política ${ }^{28}$.

Por otra parte, la ausencia de criterios para evaluar los cursos de capacitación y sensibilización en salud intercultural, sugieren que estos proyectos son banalizados por las instituciones de salud, que se realizan las acciones porque exigen lineamientos por cumplir. Mientras que el protagonismo es un marcador de la presencia de formas autoritarias que implican el rompimiento sistemático de normatividades para beneficio personal.

\section{Capacitaciones internacionales}

Una vez concluidos los cursos de sensibilización a los funcionarios de la Secretaría de Salud, la asociación civil Yolpahtli se disolvió por diferencias entre sus integrantes. Pero los contenidos fueron la base para los Diplomados internacionales en salud Intercultural, 
impartidos por profesores del Departamento de Historia y Filosofía de la Medicina de la UNAM en Ayacucho, Perú con la participación de la Universidad Mayor de San Cristóbal de Huamanga y el apoyo logístico y financiero de la agencia española Amares en el 2004 y 2006.

Bajo esta misma lógica impartí cursos y dicté conferencias para los ministerios de salud en Venezuela, Chile, Perú y México.

En términos generales, la implementación de este tipo de capacitación se realizó sobre tiempos limitados, que solo permiten abordar aspectos llamativos para las audiencias conformadas por el personal de salud, siendo notorias las ausencias de funcionarios y administrativos.

Si bien en los cursos abordábamos la salud intercultural, esta hacía alusión a acontecimientos históricos, relacionados con el otorgamiento de servicios de atención a las poblaciones indígenas; por tanto, no se profundizaba en su conceptualización, más bien se ejemplificaban casos y se definía a la salud intercultural como formas horizontales de diálogo y respeto entre culturas médicas.

Es llamativo el interés de las audiencias médicas por los temas relacionados con la cosmovisión indígena, caracterizados por destacar los aspectos culturales (simbólicos) de las "medicinas indígenas" con el fin de demostrar que se trataban de verdaderos conocimientos, como los de la medicina.

Lo anterior me llevó a reflexionar por las formas en que hemos conceptuado la cosmovisión, pues más que una construcción sociocultural histórica entre clases sociales, la abordamos de manera esencialista y hasta con tintes melancólicos sobre un pasado prehispánico.

En el caso de los modelos Médicos, si bien se aborda el pluralismo médico, resulta complicado abordar sus características estructurales, los conceptos de hegemonía-subalternidad y los condicionantes políticos económicos del proceso salud enfermedad atención.

Sin embargo, este hecho me hizo caer en cuenta que, al abordar lo indígena, habíamos silenciado las relaciones históricas de dominio económico-políticas; así como el terrible proceso de racialización que, en algunos casos, contribuyeron al surgimiento de grupos de resistencia armada y, de manera directa o indirecta, han involucrado a grandes sectores de la población en actos de violencia.
En el presente siglo, si hay algo en común en los pueblos indígenas de América, es enfrentar políticas extractivistas que han generado el despojo de sus territorios, la movilidad de grandes sectores de su población hacia los centros urbanos y la anulación de sus derechos básicos como la salud y la educación.

\section{¿Indicadores en los programas de salud intercultural?}

Durante mi última incursión a Venezuela en el 2014, en el marco de un congreso sobre salud indígena, ante la falta de recursos, nos vimos obligados a viajar a la Gran Sabana en una especie de microbús; pero el largo trayecto me permitió establecer relaciones de interlocución con los promotores de salud de varias comunidades de la Amazonia y responsables de programas de salud en Perú y Bolivia.

En nuestra ruta, nos detuvimos en un pueblo minero donde descansamos. Ante las grandes filas de autos formados para cargar gasolina, los comerciantes de alimentos que deambulaban por las calles llenas de lodo y las casonas que servían de tiendas para la venta de todo tipo de artículos, incluyendo la prostitución, era inevitable hablar del impacto de la minería en la región, el despojo de tierras a los pueblos indígenas, la contaminación del agua, la violencia generalizada, el tráfico ilegal de todo tipo de productos y la presencia de malaria y fiebre amarilla.

Si bien la Dirección de Salud Indígena del Ministerio del Poder Popular para la Salud registraba los casos de mobi-mortalidad de estas enfermedades, estas se concentraban en Caracas, pero con frecuencia los datos no eran dados a conocer, por lo que su manejo era y es interno, de este modo, nos informamos que una de las principales causas de muerte en la Amazonia venezolana es el VHI-SIDA.

Sobre los hechos expuestos, cuestioné el abordaje "culturalista" de la llamada salud intercultural, la cual considero que ha servido para silenciar lo evidente: la existencia de una morbi-mortalidad diferencial, característica de contextos de dominación, explotación y de hegemonía/subalternidad.

A mi retorno a México, visité a un amigo epidemiólogo que trabaja en la Dirección General de Epidemiología quien me aseguró la existencia de información actualizada de toda la república. Al solicitarle los datos epidemiológicos de Puebla, Oaxaca y Chiapas, me explicó que precisamente esas entidades presentan rezagos importantes en el envío de la información. 
Ante esta información, en el presente año nos dimos a la tarea de la búsqueda de datos epidemiológicos en las regiones donde se concentra la población hablante de una lengua indígena; pero no se logró generar ningún registro. Por lo que procedimos a buscar información de las regiones en donde se ubican los hospitales integrales con módulo de medicina tradicional y el resultado fue el mismo ¡No existen datos epidemiológicos!

Ante la ausencia de indicadores básicos, como los epidemiológicos, nuestra pregunta es: ¿Cómo se han evaluado los programas que tienen como base la salud intercultural? Fue así nos dimos a la tarea de recopilar toda la información posible de la Dirección de Medicina Tradicional y Desarrollo Intercultural y evaluarla bajo un enfoque biomédico.

\section{Interculturalidad en los Programas de Salud en México}

De acuerdo a la definición de la Secretaría de Salud, la interculturalidad se define como una relación entre varias culturas diferentes que se realiza con respeto y horizontalidad, es decir que ninguna se pone arriba o debajo de la otra; y maneja la propuesta de "relación intercultural equitativa que pretende empoderar a la población especialmente a la indígena, respecto a sus derechos humanos en salud, al reconocer su cultura en un marco de igualdad y respeto, generando como consecuencia la elevación de su autoestima, dignidad y reconocimiento social, además de su capacidad de interlocución y acceso a los servicios, de la misma manera y respetando el principio de horizontalidad del enfoque intercultural, proponemos dotar al personal de salud las herramientas, que les permitan establecer una relación complementaria y participativa con un usuario empoderado" 29 .

Esta política de interculturalidad en salud ha sido implementada paulatinamente por la Dirección de Medicina Tradicional y Desarrollo Intercultural, que a su vez se encuentra adscrita a la Dirección General de Planeación y Desarrollo en Salud de la Secretaría de Salud Federal.

De acuerdo con el documento denominado "Modelos interculturales de servicios de la Salud" ${ }^{\text {"30 }}$ la justificación de integrar la interculturalidad en salud es que se han identificado condiciones y problemas en la población indígena como:

- "Marginación,

- Población en localidades pequeñas y remotas, espacios de salud, equipo y abasto de medicamentos, diseñados desde la visión urbana de los servicios de salud, sin incorporar elementos de la cultura local.

- Barreras culturales del sistema, de los espacios, de los prestadores y los usuarios. Experiencias de maltrato e insatisfacción. Eventos adversos ocasionados por problemas comunicación derivados del idioma y la diversidad de cosmovisiones respecto de la salud, la enfermedad y múltiples eventos cotidianos.

- Desconfianza hacia los servicios de salud, por lo que prefieren la atención de personas propias de la comunidad que en muchas ocasiones no cuentan con la capacitación necesaria para la detección de riesgos y complicaciones médicas.

- Confrontación de la población indígena con la cultura urbana.

- Usuario desvalorizado y desempoderado."

Así mismo, se propone utilizar el enfoque intercultural para contribuir con la Cruzada Nacional para mejorar la Calidad de los Servicios de Salud, "considerando que es necesario incorporar la dimensión social y cultural del proceso salud-enfermedad-atención" ${ }^{\prime 31}$.

Sumado a lo anterior, y teniendo como base lo establecido en los Planes Nacionales de Desarrollo: 2001-2006, 2007-2012, y 2013-2018, se planteó una política intercultural dirigida a "mejorar la calidad interrelacionada de los servicios con la clara promoción de adecuaciones interculturales en la operación de los servicios de salud y en el diseño de los espacios de atención, para favorecer la sensibilidad cultural en una sociedad con características multiculturales como la nuestra". En el Plan vigente, el sustento de esta política de interculturalidad se encuentra en la Meta de un México incluyente y el Objetivo de "asegurar el acceso a los servicios de salud"; en su estrategia 2.2.3 en el que se propone fomentar el bienestar de los pueblos y comunidades indígenas.

Los objetivos de la incorporación del enfoque intercultural en los programas de salud son ${ }^{32}$ :

- Transferir a la comunidad información, conocimientos, recursos, organización e iniciativas de manera que ésta las pueda aprovechar en beneficio propio, de acuerdo con su propia percepción de la problemática.

- Promover la satisfacción de las necesidades de la población usuaria. Evitar consecuencias producto de una mala comunicación.

- Facilitar que la población participe en la planeación y evaluación de los servicios y programas, asumiendo el control de los procesos relacionados con su salud, su ambiente y su contexto social. 
- Potenciar los objetivos comunes y generar acciones conjuntas.

- Favorecer la igualdad de oportunidades de acceso a los servicios de salud.

- Fortalecer la oferta de los servicios.

- Mejorar el impacto clínico y educativo de las acciones.

- Aumentar la seguridad de las acciones terapéuticas.
La organización de los indicadores propuestos para su evaluación, tuvieron sustento en un proceso de consulta en comunidades indígenas. La Secretaría de Salud seleccionó 10 indicadores y otros a partir de una propuesta de indicadores en interculturalidad, para finalmente tener una lista de seis indicadores que se describen a continuación:

Tabla 1. Indicadores para la política de interculturalidad en salud, México.

\begin{tabular}{|c|c|}
\hline Indicador & Definición \\
\hline 1. Respeto a la libre expresión de prácticas y creencias. & $\begin{array}{l}\text { Porcentaje de usuarios satisfechos con el respeto a la libre expresión de } \\
\text { sus creencias, conceptos y prácticas sobre salud. }\end{array}$ \\
\hline 2. Satisfacción con la exploración física recibida. & Porcentaje de usuarios satisfechos con la exploración física \\
\hline 3. Satisfacción con el tiempo de atención. & Porcentaje de usuarios satisfechos con el tiempo dedicado a la atención \\
\hline 4. Uso de la lengua indígena en la unidad de salud. & Porcentaje de entrevistas que se realizan en el idioma de cada paciente \\
\hline $\begin{array}{l}\text { Satisfacción de las usuarias por un trato que permita la } \\
\text { 5. toma libre e informada de decisiones sobre su salud y } \\
\text { cuerpo. }\end{array}$ & $\begin{array}{l}\text { Porcentaje de usuarias satisfechas por el trato que les permite decidir } \\
\text { libre e informadamente sobre su salud y su cuerpo. }\end{array}$ \\
\hline $\begin{array}{l}\text { 6xistencia de condiciones de acceso a servicios } \\
\text { integrales y de buena calidad en la unidad de salud. }\end{array}$ & $\begin{array}{l}\text { Porcentaje de usuarios y de usuarias que manifestaron condiciones de } \\
\text { acceso suficientes a la unidad de salud. }\end{array}$ \\
\hline
\end{tabular}

Fuente: Secretaría de Salud. Interculturalidad en Salud. Experiencias y aportes para el fortalecimiento de los servicios de salud. Dirección General de Planeación y Desarrollo en Salud. México, 2014.

Para la selección de estos indicadores, se consideraron los siguientes criterios ${ }^{32}$ :

- "Que sean indicadores no contemplados ya en la Cruzada Nacional de la Calidad.

- Que los indicadores seleccionados agrupen otros muy específicos.

- Que sean de alta importancia para los usuarios de población indígena.

- Que haya facilidad para medirlos (tomando en cuenta que no existen recursos específicos para evaluar los indicadores)

- Que su valoración despliegue un plan de acción para facilitar un proceso de mejora de la calidad de la atención que pueda convertirse en acciones concretas."

Como se señaló, el proceso de evaluación es una herramienta que permite conocer logros, limitaciones y debilidades de los programas o sus procesos, con el fin de mejorar los mismos, para garantizar el alcance de los objetivos o metas finales.

En el caso de los programas sociales y de salud, se han establecido metodologías para ello. Entre las cuales sobresalen la Metodología del Marco Lógico (MML) y la Evaluación del Desempeño de los Sistemas de Salud. Para todos los casos, la definición de indicadores permite evaluar a través del tiempo el logro de las metas trazadas, el alcance de los objetivos y también permiten conocer el ejercicio del presupuesto designado a cada programa.

Por lo tanto, los indicadores son fundamentales en la evaluación y la vigilancia de un programa, por ello deben ser válidos, confiables, específicos, sensibles mesurables, relevantes, etc ${ }^{33}$.

De esta manera, la congruencia entre objetivos, indicadores y metas es la parte fundamental de la MML, los indicadores no sólo deben reflejar cuanto se hace en un periodo de tiempo; sino también deben evidenciar que las acciones emprendidas se relacionan con el alcance los objetivos del programa.

\section{Congruencia entre sus objetivos, indicadores y metas}

De acuerdo a los objetivos establecidos para la política intercultural, se clasificaron los seis indicadores de interculturalidad señalados anteriormente (Tabla 2), ello con el fin de dar cuenta de la concordancia entre lo establecido por el objetivo y lo estipulado por el indicador. De esta manera, se observó que los seis indicadores están asociados a conocer la percepción de las personas usuarias de los servicios recibidos, lo que corresponde con el objetivo "Promover la satisfacción de las necesidades de la población usuaria. Evitar consecuencias producto de una mala comunicación". 
De esta manera, sólo uno de los objetivos se relaciona con los indicadores propuestos y siete objetivos restantes carecen de indicadores definidos; con lo cual cabe preguntarse, sobre cómo estos pueden ser alcanzados o evaluados. Esto es relevante dado que se relacionan con la participación de la población usuaria en la planeación y evaluación de los servicios (objetivo 3), acceso a los servicios (objetivo 4), oferta de servicios (objetivo 5), impacto clínico y educativo (objetivo 5) y seguridad del paciente (objetivo 6); es decir, se encuentran relacionados con los procesos de gestión de la comunidad pero también con aspectos de la evaluación de aspectos objetivos de cualquier programa: eficiencia, eficacia, seguridad del paciente.

Respecto a oferta de servicios (objetivo 5), es decir, la cantidad de recursos con los que se cuenta para poder implementar o fortalecer un tipo de políticas. Se observa que este objetivo no cuenta con la herramienta básica o indicador para conocer la situación inicial (que podría funcionar también como un diagnóstico de situación) o para su seguimiento, con lo que cual no se visibiliza una posibilidad de mejora; si fuera el caso. Por lo tanto, se desconoce (al menos en papel) los recursos con los que se ha contado, desde que se implementó esta política.

En cuanto al objetivo 1, relacionado con la comunicación que podría establecerse entre quienes operan esta política y los beneficiarios, tampoco existe una herramienta para conocer la implementación de las distintas estrategias que faciliten el proceso, así como sus resultados. No queda claro cómo se puede evaluar el verbo "transferir" información, lo cual dificulta la definición de indicadores.

Un aspecto relevante que mencionar es, que en los documentos revisados no se logró identificar metas para un lapso definido, por lo que se desconoce cuál puede ser el alcance de los indicadores propuestos.

\section{Calidad de la atención}

Desde la perspectiva de la $\mathrm{OMS}^{34}$, la calidad de la atención médica está integrada por seis dimensiones: efectividad, eficiencia, seguridad, aceptabilidad/ atención centrada en el paciente, equidad y accesibilidad, para cada una de las dimensiones se pueden construir indicadores de acuerdo con la definición conceptual de cada una. En este apartado se realiza un análisis sobre la pertinencia de los indicadores de la política de interculturalidad en salud y su relación con el concepto de calidad de la atención médica, tomando como base la definición de la OMS.
Lo anterior por diferentes aspectos, uno de los cuales está relacionado con el propósito de la interculturalidad en salud que tiene que ver con contribuir al fortalecimiento de la calidad de la atención médica principalmente aquella dirigida a población indígena, y otro relacionado con las recomendaciones que realiza la OMS para la integración de las medicinas complementarias y tradicionales al sistema de salud de los estados parte, en el sentido de la reglamentación y evaluación de aspectos como eficiencia, eficacia, seguridad del paciente, etc. mismos que forman parte de la definición de calidad de la atención.

Dado este contexto, se realizó un comparativo de acuerdo a las dimensiones que integran el concepto de Calidad (OMS), con los indicadores propuestos para la interculturalidad en salud y también, con algunos ejemplos de indicadores que son utilizados en el área de salud, algunos utilizados por el Consejo Nacional de Evaluación de la Política de Desarrollo Social $(\text { CONEVAL })^{35}$.

En la Tabla 3 se observa que la mayoría (5) de los indicadores de interculturalidad de acuerdo con esta definición de calidad, están relacionados con la dimensión 3: Aceptabilidad/Atención centrada en el paciente, y uno con la dimensión de Equidad. Sin embargo, existe un vacío en cuanto a cómo se van a evaluar la efectividad de las intervenciones, la eficiencia, la seguridad de los pacientes y la accesibilidad.

Si bien, el programa que tiene como base la salud intercultural otorga importancia a la opinión de los usuarios sobre aspectos de la atención médica recibida; son anulados indicadores relevantes como el conocer los resultados de las intervenciones; el análisis de costo-beneficio para evaluar si el presupuesto ejercido es acorde a las metas propuestas o si las intervenciones dan los resultados justificados y por lo tanto los costos; así como los relacionados con factibilidad, o bien el conocer si los servicios ofertados son accesibles a la población dirigida.

Al no contar con indicadores, no es posible conocer avances, debilidades y la planeación de oportunidades de mejora. De igual forma no es posible evaluar la praxis ética, que se relaciona la seguridad del paciente: análisis de intervenciones o prácticas terapéuticas seguras.

En resumen, después de 15 años, la política de interculturalidad en salud no cuenta con los suficientes criterios de diseño para evaluar el cumplimiento de sus objetivos, lo cual impide conocer su impacto en los indicadores de salud o avances. 
Tabla 2. Análisis de la congruencia entre objetivos e indicadores interculturales propuestos por la Secretaría de Salud en el marco de la política de interculturalidad en salud.

\section{Objetivos del enfoque intercultural}

Indicadores interculturales

Definición operativa

1. Transferir a la comunidad información, conocimientos, recursos, organización e iniciativas de manera que éstas las pueda aprovechar en beneficio propio, de acuerdo con su propia percepción de la problemática.

Satisfacción con la exploración física recibida.

Satisfacción con el tiempo de atención.

Uso de la lengua indígena en la unidad de salud.

Satisfacción de las usuarias por un trato que permita la toma libre e informada de decisiones sobre su salud y cuerpo.

Existencia de condiciones de acceso a servicios integrales $\mathrm{y}$ de buena calidad en la unidad de salud.

Respeto a la libre expresión de prácticas y creencias.
Porcentaje de usuarios satisfechos con la exploración física.

Porcentaje de usuarios satisfechos con el tiempo dedicado a la atención.

Porcentaje de entrevistas que se realizan en el idioma de cada paciente.

Porcentaje de usuarias satisfechas por el trato que les permite decidir libre e informadamente sobre su salud y su cuerpo.

Porcentaje de usuarios que manifestaron condiciones de acceso suficientes a la unidad de salud.

Porcentaje de usuarios satisfechos con el respeto a la libre expresión de sus creencias, conceptos y prácticas sobre salud.

3. Facilitar que la población participe en la planeación y evaluación de los servicios y programas, asumiendo el control de los procesos relacionados con su salud, su ambiente y su contexto social.

4. Potenciar los objetivos comunes y generar acciones conjuntas.

5. Favorecer la igualdad de oportunidades de acceso a los servicios de salud.

6. Fortalecer la oferta de los servicios.

7. Mejorar el impacto clínico y educativo de las acciones.

8. Aumentar la seguridad de las acciones terapéuticas

Fuente: Secretaría de Salud. Interculturalidad en Salud. Experiencias y aportes para el fortalecimiento de los servicios de salud. Dirección General de Planeación y Desarrollo en Salud. México, 2014.

\section{Epílogo}

La interculturalidad en el campo de la educación, el arte y la cultura puede ser contemplada como una categoría que da cuenta del contexto y los sentidos que generan la interacción de culturas. Sin embargo; las acciones relacionadas con llamada salud intercultural son tan variadas y ambiguas, que consideró se trata de una noción. Así resulta pertinente reflexionar sobre sus diferentes usos, con el fin de dar cuenta de las lógicas socioculturales que han favorecido su permanencia y los contextos que tiende a silenciar. 
Tabla 3. Análisis comparativo entre las dimensiones que integran la calidad de la atención médica (OMS) y los indicadores de interculturalidad.

\begin{tabular}{|c|c|c|c|c|}
\hline $\begin{array}{l}\text { Dimensiones } \\
\text { Calidad* }\end{array}$ & Definición conceptual & Ejemplos de indicadores & $\begin{array}{c}\text { Indicadores } \\
\text { Interculturalidad }^{* * *}\end{array}$ & Definición operacional \\
\hline 1. Efectividad & $\begin{array}{l}\text { Atención basada en } \\
\text { evidencia que produce } \\
\text { mejora en los resultados } \\
\text { a nivel individual y } \\
\text { comunitario. }\end{array}$ & $\begin{array}{l}\text { Tasas de mortalidad en una población } \\
\text { determinada. } \\
\text { Tasas de incidencia de enfermedades crónicas. }\end{array}$ & & \\
\hline 2. Eficiencia & $\begin{array}{l}\text { Atención sanitaria que } \\
\text { maximiza los recursos y } \\
\text { evita despilfarro. }\end{array}$ & $\begin{array}{l}\text { Disponibilidad de los servicios de salud: } * * * \\
\text { - Establecimientos de salud por cada mil } \\
\text { personas; } \\
\text { - Camas censables disponibles por cada mil } \\
\text { personas } \\
\text { - Camas no censables disponibles por cada mil } \\
\text { personas } \\
\text { - Equipo médico disponible por cada mil } \\
\text { personas } \\
\text { - Médicos en contacto con pacientes por cada } \\
\text { mil personas } \\
\text { - Enfermeras en contacto con paciente por cada } \\
\text { mil personas }\end{array}$ & & \\
\hline 3. Seguridad & $\begin{array}{l}\text { Atención sanitaria que } \\
\text { minimiza riesgos y daños a } \\
\text { los pacientes. }\end{array}$ & $\begin{array}{l}\text { Fallos de atención urgente } \\
\text { Infección asociada a cuidados médicos }\end{array}$ & & \\
\hline \multirow{5}{*}{$\begin{array}{l}\text { 4. Aceptabilidad/ } \\
\text { Atención centrada } \\
\text { en el paciente }\end{array}$} & \multirow{5}{*}{$\begin{array}{l}\text { Atención que toma en } \\
\text { cuenta las preferencias } \\
\text { y aspiraciones de los } \\
\text { usuarios y la cultura de la } \\
\text { comunidad. }\end{array}$} & \multirow{5}{*}{$\begin{array}{l}\text { Percepción de los individuos sobre la adecuación } \\
\text { de los servicios a sus necesidades: } * * * \\
\text { - Porcentaje de personas que no fueron atendidas } \\
\text { al presentar un problema de salud. } \\
\text { - Motivo por el que las personas no fueron } \\
\text { atendidas al presentar un problema de salud. } \\
\text { - Porcentaje de personas hospitalizadas que } \\
\text { consideran muy buen o buena la calidad del } \\
\text { servicio durante su hospitalización. } \\
\text { - Porcentaje de personas que no regresarían al } \\
\text { lugar de hospitalización. }\end{array}$} & $\begin{array}{l}\text { Respeto a la libre } \\
\text { expresión de prácticas y } \\
\text { creencias. }\end{array}$ & $\begin{array}{l}\text { Porcentaje de usuarios } \\
\text { satisfechos con el respeto } \\
\text { a la libre expresión de sus } \\
\text { creencias, conceptos y } \\
\text { prácticas sobre salud }\end{array}$ \\
\hline & & & $\begin{array}{l}\text { Satisfacción con la } \\
\text { exploración } \\
\text { recibida. }\end{array}$ & $\begin{array}{l}\text { Porcentaje de usuarios } \\
\text { satisfechos con la exploración } \\
\text { física }\end{array}$ \\
\hline & & & $\begin{array}{l}\text { Satisfacción con el } \\
\text { tiempo de atención. }\end{array}$ & $\begin{array}{l}\text { Porcentaje de usuarios } \\
\text { satisfechos con el tiempo } \\
\text { dedicado a la atención }\end{array}$ \\
\hline & & & $\begin{array}{l}\text { Satisfacción de las } \\
\text { usuarias por un trato que } \\
\text { permita la toma libre e } \\
\text { informada de decisiones } \\
\text { sobre su salud y cuerpo. }\end{array}$ & $\begin{array}{l}\text { Porcentaje de usuarias } \\
\text { satisfechas por el trato que } \\
\text { les permite decidir libre e } \\
\text { informadamente sobre su } \\
\text { salud y su cuerpo. }\end{array}$ \\
\hline & & & $\begin{array}{l}\text { Existencia de } \\
\text { condiciones de acceso } \\
\text { a servicios integrales y } \\
\text { de buena calidad en la } \\
\text { unidad de salud. }\end{array}$ & $\begin{array}{l}\text { Porcentaje de usuarios que } \\
\text { manifestaron condiciones de } \\
\text { acceso suficientes a la unidad } \\
\text { de salud. }\end{array}$ \\
\hline 5. Equidad & $\begin{array}{l}\text { Atención sanitaria que no } \\
\text { varía en su calidad según } \\
\text { características personales } \\
\text { tales como género, raza, } \\
\text { etnicidad, ubicación } \\
\text { geográfica o estatus } \\
\text { socioeconómico. }\end{array}$ & $\begin{array}{l}\text { Utilización de servicios: } * * * \\
\text { - Porcentaje de personas que reportan sí haber } \\
\text { recibido atención a sus problemas de salud en } \\
\text { los últimos doce meses. } \\
\text { - Porcentaje de personas que reportan haber } \\
\text { recibido atención a sus problemas de salud en } \\
\text { las últimas dos semanas. } \\
\text { - De las personas que recibieron atención } \\
\text { por sus problemas de salud, porcentaje de } \\
\text { personas que sí fueron atendidas por personal } \\
\text { de salud. }\end{array}$ & $\begin{array}{l}\text { Uso de la lengua indígena } \\
\text { en la unidad de salud. }\end{array}$ & $\begin{array}{l}\text { Porcentaje de entrevistas que } \\
\text { se realizan en el idioma de } \\
\text { cada paciente }\end{array}$ \\
\hline 6. Accesibilidad & $\begin{array}{l}\text { Atención sanitaria } \\
\text { oportuna en el tiempo, } \\
\text { geográfica razonable, y } \\
\text { provista de entornos y con } \\
\text { personal adecuados a las } \\
\text { necesidades. }\end{array}$ & $\begin{array}{l}\text { Tiempos de traslado: } * * * \\
\text { - Tiempo promedio de traslado al hospital la } \\
\text { última vez que se tuvo una emergencia. } \\
\text { - Tiempo promedio estimado de traslado } \\
\text { al hospital en caso de presentarse una } \\
\text { emergencia. }\end{array}$ & & \\
\hline
\end{tabular}

Fuente: * World Health Organization. Quality of care. A process for making strategic choices in health systems. France, 2006

${ }^{* *}$ Secretaría de Salud. Interculturalidad en Salud. Experiencias y aportes para el fortalecimiento de los servicios de salud. Dirección General de Planeación y Desarrollo en Salud. México, 2014.

*** Consejo Nacional de Evaluación de la Política de Desarrollo Social, CONEVAL. Indicadores de acceso y uso efectivo de los servicios de salud de afiliados al Seguro Popular. $1^{\mathrm{a}}$ ed. México, 2014. 
En lo personal, consideramos que las secretarías y ministerios de salud; hacen referencia de enfoque intercultural en salud para justificar las acciones gubernamentales hacia los pueblos indígenas; sin embargo, la banalización de los indicadores de salud y su expresión diferencial; nos permiten identificarla como una política retórica y racializadora ${ }^{36}$, que al codificar a los indígenas como "marginal" y exotizarle, tiende a silenciar las relaciones históricas de subordinación económica y política ${ }^{37}$.

Tal y como lo afirmara el Dr. Jaime Ibacache, en un encuentro de Asociación Latinoamericana de Medicina Social del 2009: "la interculturalidad en salud se ha convertido en la política neoliberal de salud para los pueblos indígenas de América”.

En México, el llamado enfoque intercultural de salud apuesta a la capacitación o sensibilización del personal de salud para lograr la "transformación de los servicios de servicios de salud para asegurar el acceso efectivo de la población"; "servicios y atención médica de calidad"; así como de fomentar la participación y respuesta asertiva de la población. Incluso en Chile se destaca la importancia de contemplar la participación de la población indígena en todas las etapas de la implementación de los proyectos de salud. No obstante, en ambos países si algo han hecho estás políticas; es anular de manera paulatina y silenciar las formas de gestión de los pueblos indígenas ${ }^{38}$.

Por otra parte, al no abordar las históricas relaciones de subordinación que enfrentan las poblaciones indígenas; no es nada claro, cómo la participación en los servicios de salud mejorará sus condiciones de salud. ${ }^{39}$ En el mejor de los casos, se deduce que lo hará como usuario, al hacer uso de las adecuaciones culturales realizadas en los hospitales o clínicas.

Ramírez Hita ${ }^{40}$ señala que en Bolivia los trabajos sobre desarrollo, realizados en su mayoría por agencias nacionales e internacionales también se caracterizan por la descripción del éxito en la implementación de un proyecto, y por el hecho de utilizar una metodología participativa destacando particularmente el aspecto sociocultural. Estos evidencian una ambigüedad y confusión teórica producto del uso de metodologías como los Diagnósticos de Evaluación Rápida (RAT por sus siglas en inglés), que bajo criterios de costo/ beneficio promueven una rápida intervención en terreno dejando poco lugar para la evaluación.

El acceso restringido a la información epidemiológica y/o programas impulsados en las regiones que concentra hablantes de lenguas indígenas; impiden evaluar si objetivos planteados por las políticas interculturales en salud se han alcanzado o muestran limitantes. En el mejor de los casos, el poco registro etnográfico y algunas poblaciones sugieren una mejoría en la calidad de la atención; aunque los indicadores relacionados con la mortalidad materna no sugieren mejorías significativas.

Sería prudente que los investigadores sociales y en particular, los antropólogos que han decidido asesorar a las instancias gubernamentales, negocien la realización de epidemiologías socioculturales con la intención de dar cuenta de los factores relacionales que origina la mobi-mortalidad diferencial y, a partir de ese análisis, generar propuestas de intervención. Otra opción sería cuestionar el manejo discreto de los perfiles epidemiológicos por parte de los Ministerios de Salud, lo que permitiría evaluar los impactos de una estrategia que, a casi dos décadas, tiene como fundamento la llamada interculturalidad y en los indicadores de bienestar.

No obstante, mis recientes investigaciones en hospitales del Estado de Oaxaca, México, me han llevado a reconocer y reflexionar sobre las condiciones económicas y políticas que enfrenta la población empobrecida; pero también en las condiciones adversas que enfrentan los profesionales de la salud y, en general, todo el personal que labora en los hospitales y clínicas, producto de la corrupción.

El desvío sistemático de los fondos federales para el sector salud ha generado el recorte de presupuesto financiero e incluso la cancelación de los servicios médicos destinados a las poblaciones empobrecidas y/o indígenas. No obstante, las instancias oficiales han permanecido en silencio al respecto.

Ejemplo de ello se expresa en hospital público más importante de la entidad, pues ha perdido todas las "certificaciones". Al dejar de percibir fondos federales para los programas de atención, se ha visto obligado a reutilizar material médico de desecho (catéter) y a priorizar los casos de "urgencia", quedando abandonados la mayor parte de los pacientes.

La situación desencadenó confrontaciones entre los médicos y los familiares de los enfermos; pero incluso entre los profesionales de la salud pues cada uno ha intentado priorizar la atención de sus pacientes. Es notorio observar el rompimiento de protocolos de atención clínica; malas condiciones del instrumental médico, el hacinamiento de enfermos en los cuartos y 
pasillos; la ausencia de personal de seguridad. Mientras que el área de archivo recibió la orden de no proporcionar ninguna información. En el lapso de un año, cuatro pediatras han presentado problemas cardíacos.

Así el estudiar la corrupción en el sector salud de Oaxaca, me ha llevado a reconocer un silenciamiento que es acompañado por el rompimiento de normatividades. El predominio de un autoritarismo que no puede ser cuestionado; que se sustenta en el miedo y que termina por anular los derechos de los sectores empobrecidos y de los profesionales de la salud, como si se tratara de una configuración sociocultural de un estado de excepción.

A partir de reconocer este contexto, me he hecho las siguientes preguntas: si se lograra registrar la morbimortalidad de la población indígenas, los programas ¿impactarían en los indicadores de bienestar? ¿Cambiarían las formas de financiamiento del sector salud, la formación en recursos humanos, etc.? Quizás sólo lograríamos dar cuenta de una mortalidad diferencial.

Otro aspecto por reflexionar en torno a la salud intercultural son las diversas audiencias, que legitiman las formas socioculturales de dominio. Entre otros, me refiero a las universidades interculturales y sectores sociales que he denominado global-melancólicos que mediante los medios de comunicación masiva han recreado las nociones sobre el diálogo respetuoso entre las culturas ancestrales y la biomedicina.

En el medio académico, es notorio el aumento de publicaciones impresas y electrónicas que hacen referencia a la interculturalidad en salud ${ }^{41}$. He detectado un enfoque denominado de-colonial que propone la ecología del reconocimiento para lograr un diálogo respetuoso de saberes ${ }^{42}$. Incluso se asevera que en México es un tema dominante en los estudios de la Antropología Médica ${ }^{25}$.

Una consideración final. Pierre Bourdieu en su obra la miseria del mundo ${ }^{43}$ nos muestra que el investigador social puede descifrar las estrategias de dominación. Así el trabajo sociológico tiene implicaciones políticas, al cuestionar las lógicas que mantiene el orden social existente y al apoyar las acciones emancipadoras. Pero también nos advierte sobre los riesgos de convertirse en instrumento de los juegos políticos, al subordinarse a las estrategias de dominación directas o indirectas. Apelar al enfoque reflexivo podría ayudar tener claridad en nuestra postura política y las implicaciones de nuestro trabajo, aunque eso no se vea reflejado en los estímulos académicos

\section{Referencias}

1. Rossi I. Cap 2. La clínica como espacio social ¿Época de cambios o cambio de época? En: Liz Sutton L, Paulo Maya A, Hernández Torres I. La comunicación dialógica como competencia médica esencial. 1a Ed. México: El Manual Moderno, 2018.

2. Marcus GE. Etnografía en/del sistema mundo. El surgimiento de la etnografía multilocal. Alteridades. 2001; 11(22): 111-127.

3. Vega RA. I(nter)dentificación racial: racialización de la salud materna a través del programa Oportunidades y clínicas gubernamentales en México. Sal Colectiva. 2017; 13(3): 489-505. doi: http://dx.doi.org/10.18294/sc.2017.1114.

4. Aull Davies C. Reflexive Ethnography. London: Routledge. 1999; 257.

5. Ghasarian C . De la etnografía a la antropología reflexiva: Nuevos campos, nuevas prácticas, nuevas apuestas. Serie Antropologia. Ediciones Quinto sol. Argentina. 2008; 264.

6. Ramírez Hita S. Salud intercultural. Crítica y problematización a partir del contexto boliviano. La Paz, Bolivia: Inst Superior Ecuménico Andino de Teología. 2011; p: 181.

7. Menéndez E. La parte negada de la cultura: relativismo, diferencias y racismo. 2a ed. Rosario: Prohistoria Ediciones, 2010; 412 p.

8. Molina N. How race is made in america: immigration, citizenship, and the historical power of racial. Berkeley: University of California Press. 2014. 208 p.

9. Ibacache J. La salud, el desarrollo y la equidad en un contexto intercultural; 1997.

10. MINSAL. Programa especial de salud y pueblos Indígenas. Santiago, Chile.

11. Cuyul A. La burocratización de la salud intercultural. Del neo-asistencialismo al autogobierno mapuche en salud; 2010.

12. MINSAL - Banco Mundial. Plan para pueblos Indígenas. Proyecto de apoyo al sector salud. Santiago. 2017; p: 6.

13. MINSAL. Informe de Seguimiento de Programas Sociales. Programa Especial de Salud y Pueblos Indígenas (PESPI); 2016.

14. Cheuquepán S, Henríquez J, Bustos B. Orientaciones técnicas y guía metodológica: programa especial de salud y pueblos indígenas. Chile: MINSAL; 2016.

15. MINSAL. Perfil epidemiológico básico de la población Aymara del Servicio de Salud Arica. 
Serie Análisis de Situación de Salud de los Pueblos Indígenas de Chile No. 001. Santiago, Chile: 2006.

16. MINSAL. Perfil epidemiológico básico de la población Mapuche-williche residente en el área de cobertura de los Servicios de Salud Chiloé y del Reloncaví. Serie análisis de situación de salud de los pueblos indígenas de Chile No. 10. Santiago, Chile; 2013.

17. Cuyul A. Machi terrorista o machi esterilizada: Persecución política y criminalización de autoridades tradicionales mapuche en Chile; 2014.

18. Uribe M, Abrantes R. Las reformas a la protección social en salud en México: ¿rupturas o continuidades? Perf Latinoam. 2013; 21(42): 135-162

19. Korsbaek L, Sámano-Rentería MA. El indigenismo en México: antecedentes y actualidad. Ra Ximhai. 2007; 3(1): 195-224.

20. Ley Indígena. Rev Nexos. 2001.

21. Campos Navarro R, Peña Sánchez EY, Paulo Maya A. Aproximación crítica a las políticas públicas en salud indígena, medicina tradicional e Interculturalidad en México (1990-2016). Sal Colectiva. 2017; 13(3): 443-455. doi: http://dx.doi. org/10.18294/sc.2017.1115.

22. Secretaría de Salud. Medicina tradicional y desarrollo intercultural. México; 2018.

23. Bonfil G. México profundo. Una civilización negada. México, DF: Editorial Grijalbo, 1994.

24. Campos R. La enseñanza de la antropología médica y la salud intercultural en México: del indigenismo culturalista del siglo xx a la Interculturalidad en salud del siglo XXI. Revista de Medicina Experimental y Salud Pública, 2010. 27(1): 114-122. doi: http:// dx.doi.org/10.17843/rpmesp.2010.271.1451

25. Duarte-Gómez MB, Campos-Navarro R, Nigenda G. Medical anthropology in Mexico: recent trends in research and education. En: Francine Saillant (Editor). Medical Anthropology: regional perspectives and shared concerns. Oxford: Blackwell; 2007.

26. Duarte-Gómez MB, Brachet-Marquez V, CamposNavarro R, Nigenda G. Políticas nacionales de salud y decisiones locales en México: el caso del Hospital Mixto de Cuetzalan, Puebla. Sal Pública Mex. 2004; 46(5): 388-398.

27. Yolpahtli SC. Interculturalidad en Salud. Práctica médica con pueblos Indígenas de México. 2003.

28. Menéndez E. Interculturalidad, "diferencias" y Antropología "at home": algunas cuestiones metodológicas. En: Fernández Juárez G. Salud e interculturalidad en América Latina: antropología de la salud y crítica intercultural. España: Universidad de Castilla-La Mancha. 2006; p. 51-66.
29. Secretaría de Salud. El enfoque intercultural: Herramienta para apoyar la calidad de los servicios de salud. México: 2003; 4-10

30. Almaguer JA. Mesa redonda IX. Modelos interculturales de servicios de salud. DGPLADES, México: 2016.

31. Almaguer JA. El enfoque intercultural, herramienta para apoyar la calidad de los Servicios de Salud. DGPLADES, México: 2003.

32. Secretaría de Salud. Interculturalidad en Salud. Experiencias y aportes para el fortalecimiento de los servicios de salud. Dirección General de Planeación y Desarrollo en Salud. México: 2014.

33. Di Virgilio MM. Monitoreo y evaluación de políticas, programas y proyectos sociales. $1^{\mathrm{a}} \mathrm{Ed}$. Buenos Aires: Fundación CIPPEC, UNICEF, 2012.

34. World Health Organization. Quality of care. A process for making strategic choices in health systems. France: 2006.

35. Consejo Nacional de Evaluación de la Política de Desarrollo Social, CONEVAL. Indicadores de acceso y uso efectivo de los servicios de salud de afiliados al Seguro Popular. 1a ed. México, 2014.

36. Vega RA. Hacia la justicia sociocomunicativa: trabajo de campo multi-situado, teoría transnacional e hiper-auto-reflexividad. Rev CONAMED. 2016; 21:(S2): 76-80.

37. Bolados P. Neoliberalismo multicultural en el chile postdictadura. La política indígena en salud y sus efectos en comunidades mapuches y atacameñas. Chungara. 2012; 44(1): 135-144.

38. Mocellin M, Paulo A. ¿La interculturalidad en salud, involucra la participación de los pueblos indígenas? Rev Cult Andina. 2012; 6.

39. Menéndez, E. Participación social en salud como realidad técnica y como imaginario social. En: Cuadernos Médico/Sociales. 2010, 73: 5-22.

40. Ramírez Hita S. Salud intercultural. crítica y problematización a partir del contexto boliviano. Instituto Superior Ecuménico Andino de Teología, La Paz, Bolivia. Avá Rev Antropol. 2011; 19: 379-385.

41. Álvarez Cárdenas SL. Salud Intercultural como Política Social. Dissertação apresentado ao Programa de Pós-graduação do Instituto de Saúde Coletiva ISC-UFBA, como requisito parcial para obtenção do grau de mestre em Saúde Comunitária. Área de concentração Ciências Sociais em saúde; Brasil; 2014.

42. Stivanello MB. Aportes al debate de la Interculturalidad en Salud. Margen Rev Tra Soc Ciencias Social. 2015; 76:e 0327-7585.

43. Bourdieu P. La miseria del mundo. 1a edición, 5a reimpresión. Argentina: FCE. 2013; 564 p. 